\title{
microRNA 421 induces apoptosis of c-33a cervical cancer cells via down-regulation of Bcl-xL
}

\author{
X.J. Lai ${ }^{1}$, X.Y. Cheng ${ }^{1}$ and L.D. Hu ${ }^{2}$ \\ ${ }^{1}$ Department of Gynecology and Obstetrics, \\ Lishui People's Hospital, Wenzhou, Zhejiang, China \\ ${ }^{2}$ Department of Gynecology and Obstetrics, \\ Women and Children Health Hospital of Tonglu, Zhejiang, China \\ Corresponding author: X.J. Lai \\ E-mail: xiaojunlaibnm@sina.com
}

Genet. Mol. Res. 15 (4): gmr15048853

Received June 6, 2016

Accepted September 1, 2016

Published November 21, 2016

DOI http://dx.doi.org/10.4238/gmr15048853

Copyright $(2016$ The Authors. This is an open-access article distributed under the terms of the Creative Commons Attribution ShareAlike (CC BY-SA) 4.0 License.

\begin{abstract}
Cervical cancerisalife-threatening condition.MicroRNAs (miRNAs) can promote or inhibit cell death and proliferation. The present study investigated the effect of miRNA 421 on the growth and apoptosis of cervical cancer cells. miRNA 421 and control miRNA were synthesized and transfected into c-33a cervical cancer cells. A thiazolyl blue tetrazolium bromide assay, caspase- 3 activity, and flow cytometry were used to study the effects of miRNA 421 on c-33a cell growth, and apoptosis. Small interfering RNA targeting Bcl-xL was synthesized and transfected into c-33a cells along with miRNA 421. Bcl-xL expression and cell apoptosis were then measured by western blot and flow cytometry, respectively. Transfection of miRNA 421 into c-33a cells reduced their growth, promoted their apoptosis (measured by increased phosphatidylserine eversion), activated caspase-3, and decreased Bcl-
\end{abstract}

Genetics and Molecular Research 15 (4): gmr15048853 
$\mathrm{xL}$ expression. Silencing and overexpression of Bcl-xL enhanced and inhibited miRNA 421-induced apoptosis of c-33a cells, respectively. miRNA 421 induces c-33a cell apoptosis via down-regulation of Bcl$\mathrm{xL}$, suggesting that this latter might be used as a potential clinical target.

Key words: miRNA 421; Bcl-xL; Cervical cancer c-33a cells; Apoptosis

\section{INTRODUCTION}

Cervical cancer is a malignancy of the female reproductive system with an incidence rate of $0.03 \%$ (Kong et al., 2015). A variety of causes have been identified, of which, viral infections, sex, and frequency of childbirth are the main etiological factors (Jia et al., 2016). Cervical cancer is a life-threatening disease (Cong et al., 2015; Li et al., 2015). Although appropriate individualized treatment plans and integrated treatment regimens are effective, these approaches have shortcomings, including bleeding and other side effects (Bonetta et al., 2015; Bumrungthai et al., 2015; Song et al., 2015). Improving the specificity and success rate of cervical cancer treatment is an important and challenging goal for the medical and scientific communities. Targeted molecular therapy has become a focus of research concerning the treatment of cervical cancer (Deng et al., 2015; Lin et al., 2015; Liu et al., 2015). Targeting inhibitors of apoptosis proteins as a treatment for this condition has yielded poor results (Honegger et al., 2015); therefore, more effective molecular targets are needed (Bhattacharjya et al., 2015; Honegger et al., 2015). Moreover, targeting microRNAs (miRNAs) has not been attempted in cervical cancer treatment (Bhattacharjya et al., 2015).

miRNAs perform a variety of functions. miRNA-218 can inhibit the growth of cervical cancer cells, and miRNA-34a is associated with tumor metastasis (Geng et al., 2015; Kogo et al., 2015). Thus, miRNAs may be involved in the occurrence and development of cervical cancer (Lao et al., 2014; Geng et al., 2015; Kogo et al., 2015). In previous studies, specific primers were designed to measure miRNA expression in cervical cancer tissues and adjacent normal tissues by real-time polymerase chain reaction. Expression of miRNA 421 was found to be significantly higher in tumor tissues than in healthy tissue specimens, suggesting that it may play a role in cervical oncogenesis and its progression (Chang et al., 2014; Yuan et al., 2014).

The present study used c-33a cervical cancer cells to investigate the role of miRNA 421 in this malignancy. The aim of anti-cancer therapy is to kill tumor cells without affecting normal cells. Apoptosis is regulated by both anti- and pro-apoptotic proteins (Pedroza-Torres et al., 2014; Wen et al., 2015); therefore, the ideal anti-cancer drug would increase the effects of the latter and decrease those of the former. Bcl-xL is a widely studied anti-apoptotic protein (Zhang et al., 2013; $\mathrm{Yu}$ et al., 2014). Although many anti-cancer drugs target Bcl-xL, the effects of its down-regulation have not been as beneficial as expected (Huang et al., 2013). This study also tested Bcl-xL as a potential target, by using c-33a cells as a model to investigate the role of miRNA 421 in cervical cancer, providing a theoretical basis for targeted molecular therapy for this disease.

\section{MATERIAL AND METHODS}

\section{Reagents and cells}

c-33a cervical cancer cells were purchased from the American Type Culture Collection

Genetics and Molecular Research 15 (4): gmr15048853 
(Manassas, VA, USA). Fetal bovine serum and cell culture medium were sourced from Hualan Biological Co. (Beijing, China). A liposome transfection kit (Lipofectamine 2000) was provided by Invitrogen (Carlsbad, CA, USA). Thiazolyl blue tetrazolium bromide (MTT) assay reagents were manufactured by Beijing Dingguo Co. (Beijing, China). Apoptosis detection reagents, a caspase-3 assay kit, a protein extraction kit, and a bicinchoninic acid (BCA) protein assay kit were purchased from Biyuntian Biotechnology Institute (Haimen, China). Mouse anti-human Bcl-xL antibody was provided by Santa Cruz Biotechnology (Dallas, TX, USA). miRNA 421, control miRNA, and Bcl-xL plasmids were made by Jima Biotechnology Co., Ltd. (Shanghai, China). Sequences for miRNA 421 and control miRNA were 5'-TCA GGT CAT CAC TAT CGG CAA T-3' and 5'-AAA GAA AGG GTG TAA AAC GCA-3', and sequences for Bcl-xL small interfering RNA (siRNA) and siRNA control were 5'-CTA TGA GGC TAC CAT CGT GC-3' and 5'-TTT CAC TAC GAT TAA GCG T-3'.

\section{Cell culture}

c-33a cervical cancer cells were cultured in high-glucose Dulbecco's modified Eagle's medium according to a previously published method (Liu et al., 2015).

\section{Transfection}

miRNA 421 and control miRNA were transfected into c-33a cells following the manufacturer protocol. One microgram of miRNA or control miRNA was mixed with Lipofectamine 2000 and transfected into cells when they had reached $80 \%$ confluency.

\section{MTT assay of cell viability}

The MTT test was performed according to standard methods (Lin et al., 2015). MTT solution was placed in each well and incubated with cells for $24 \mathrm{~h}$. Dimethyl sulfoxide $(100 \mu \mathrm{L}$ per well) was then added to stop the reaction. Optical density at $560 \mathrm{~nm}$ was recorded using a microplate reader to plot a cell growth curve (Honegger et al., 2015).

\section{Measurement of apoptosis by flow cytometry}

Flow cytometry was performed according to established methods to detect apoptosis of c-33a cells. Briefly, c-33a cells were transfected with either miRNA 421 or control miRNA and cultured for $48 \mathrm{~h}$. Cells were then collected and resuspended. Reaction buffer $(100 \mu \mathrm{L})$ and fluorescein isothiocyanate-conjugated annexin V $(2 \mu \mathrm{L})$ were added to a $500-\mu \mathrm{L}$ cell suspension, which was then mixed and incubated for $25 \mathrm{~min}$ in the dark for flow cytometry analysis (Kogo et al., 2015).

\section{Western blot}

c-33a cells transfected with either miRNA 421 or control miRNA were collected and their proteins extracted and quantified using a BCA kit following the manufacturer protocol. Equal amounts of protein were electrophoresed and transferred to membranes, which were subsequently blocked. After being washed with Tris-buffered saline with Tween 20 (TBST),

Genetics and Molecular Research 15 (4): gmr15048853 
membranes were incubated with primary antibodies overnight at $4^{\circ} \mathrm{C}$. Following further washing with TBST, membranes were incubated with secondary antibodies (diluted 1:2500) for $3 \mathrm{~h}$ at $37^{\circ} \mathrm{C}$, and proteins subsequently visualized by enhanced chemiluminescence. Bcl-xL expression levels were analyzed with the Gel-Pro Analyser 4.0 software (Bio-Rad Laboratories, Hercules, CA, USA; Lao et al., 2014).

\section{Caspase-3 activity assay}

Caspase-3 activity was detected following the kit manufacturer protocol. Briefly, c-33a cells were transfected with either miRNA 421 or control miRNA and cultured for $48 \mathrm{~h}$. Cells were then collected, lysed, mixed with chromogenic substrate, and incubated at room temperature. The absorbance of each sample was recorded with a microplate reader (Yuan et al., 2014). Absorbance of c-33a cells transfected with control miRNA was subtracted from that of those transfected with miRNA 421 to determine relative caspase-3 activity.

\section{Effect of Bcl-xL up- or down-regulation on miRNA 421-transfected c-33a cells}

c-33a cells were transfected with either Bcl-xL expression plasmids or siRNA targeting Bcl-xL. These cells were then further transfected with miRNA 421 or control miRNA using Lipofectamine 2000. One microgram of Bcl-xL siRNA or Bcl-xL plasmid, and separately, $4 \mu \mathrm{g}$ control miRNA or miRNA 421, was suspended in Lipofectamine 2000. These DNA/ liposome mixtures were then added drop-wise to the cell culture medium.

\section{Statistical analysis}

SPSS 11.0 (SPSS Inc., Chicago, IL, USA) was used for statistical analysis. All experiments were repeated three times, and data are reported as means \pm standard errors. Differences between groups were analyzed using the $t$-test, with $\mathrm{P}<0.05$ being considered statistically significant.

\section{RESULTS}

\section{miRNA 421 transfection reduced viability of c-33a cells and inhibited their growth}

The MTT assay showed that miRNA 421 transfection significantly reduced the viability of $\mathrm{c}-33 \mathrm{a}$ cells, compared with those transfected with control miRNA $(\mathrm{P}=0.0066)$. No significant difference was observed between c-33a cells transfected with control miRNA and non-transfected c-33a cells. Therefore, the former were used as controls in this study (Figure 1).

\section{miRNA 421 transfection increased the apoptosis of c-33a cells}

Flow cytometry analysis revealed (Figure 2) that transfection with miRNA 421 significantly increased the presence of phosphatidylserine on c-33a cells, compared to those transfected with control miRNA $(\mathrm{P}=0.009)$.

Genetics and Molecular Research 15 (4): gmr15048853 


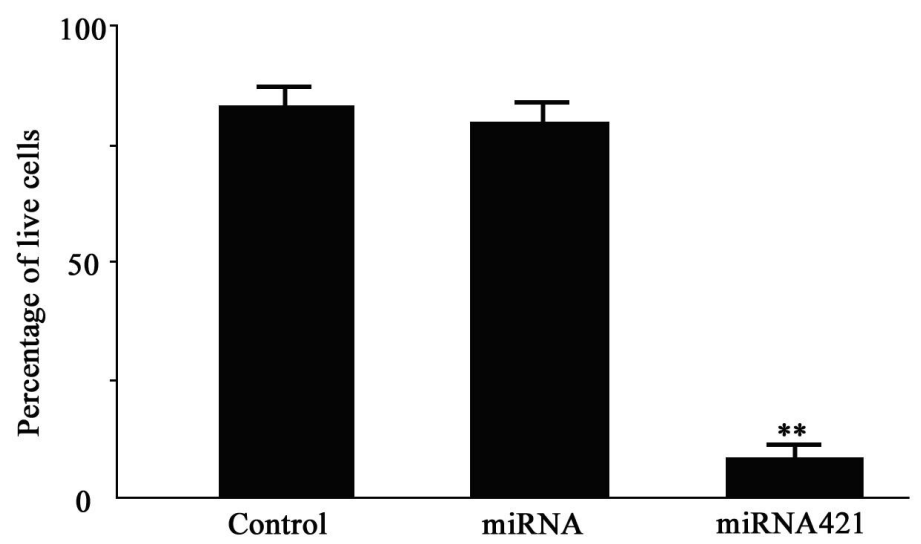

Figure 1. miRNA 421 transfection inhibited the growth of c-33a cells. A thiazolyl blue tetrazolium bromide assay was used to analyze the viability of non-transfected c-33a cells and those transfected with control miRNA or miRNA 421. ${ }^{* *} \mathrm{P}<0.01$ compared to the control miRNA group.
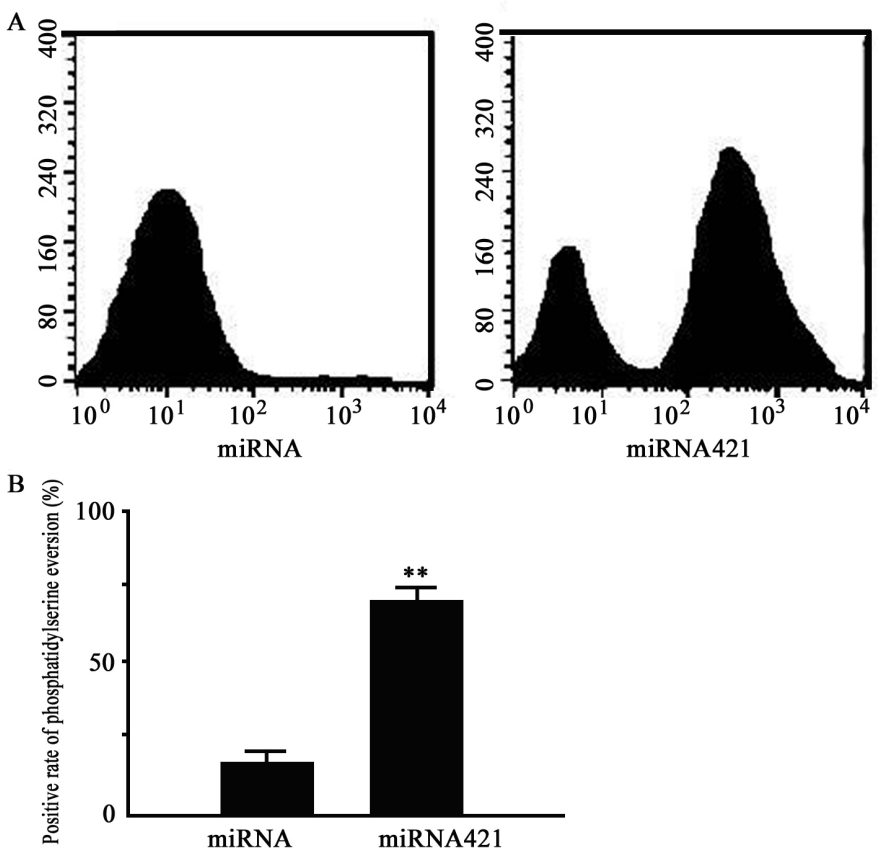

Figure 2. miRNA 421 transfection induced apoptosis of c-33a cells. Flow cytometry was used to analyze apoptosis of non-transfected c-33a cells and those transfected with control miRNA or miRNA 421. A. Flow cytometry analysis. B. Presence of phosphatidylserine on c-33a cells. ${ }^{* *} \mathrm{P}<0.01$ compared to the control miRNA group.

\section{miRNA 421 transfection activated caspase-3 in c-33a cells}

The caspase-3 activity assay demonstrated (Figure 3) that miRNA 421 transfection significantly activated this enzyme in c-33a cells, compared to the control miRNA-transfected group $(\mathrm{P}=0.031)$. 


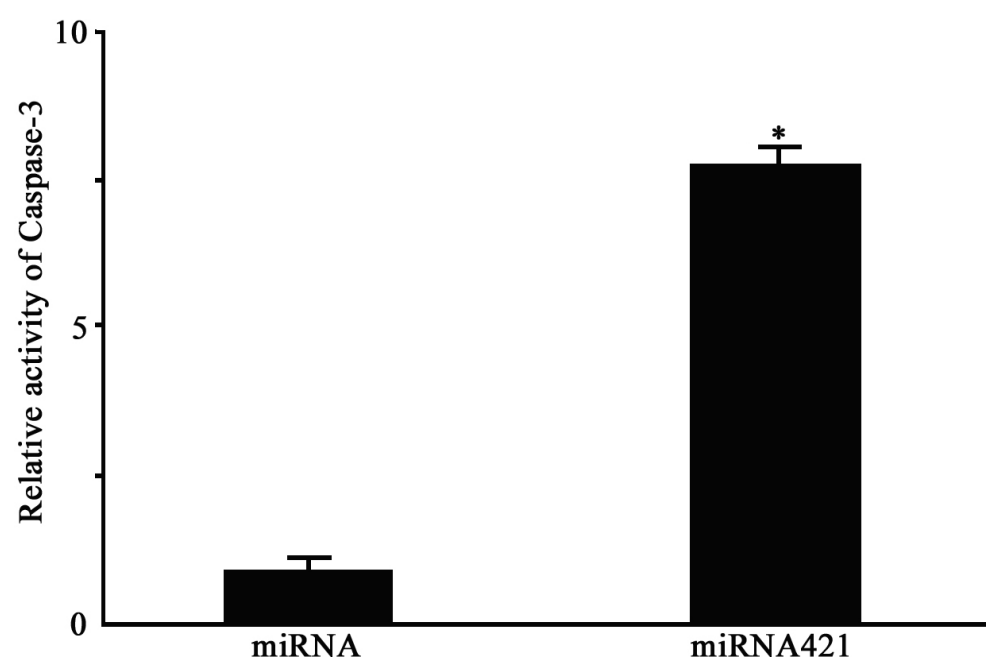

Figure 3. miRNA 421 transfection activated caspase-3 in c-33a cells. A caspase-3 assay was used to measure the activity of this enzyme in non-transfected c-33a cells and those transfected with control miRNA or miRNA 421. *P $<0.05$ compared to the control miRNA group.

\section{miRNA 421 transfection decreased Bcl-xL protein expression in c-33a cells}

Western blotting showed that transfection with miRNA 421 significantly reduced expression of Bcl-xL protein in c-33a cells, compared with those transfected with control miRNA (Figure 4).

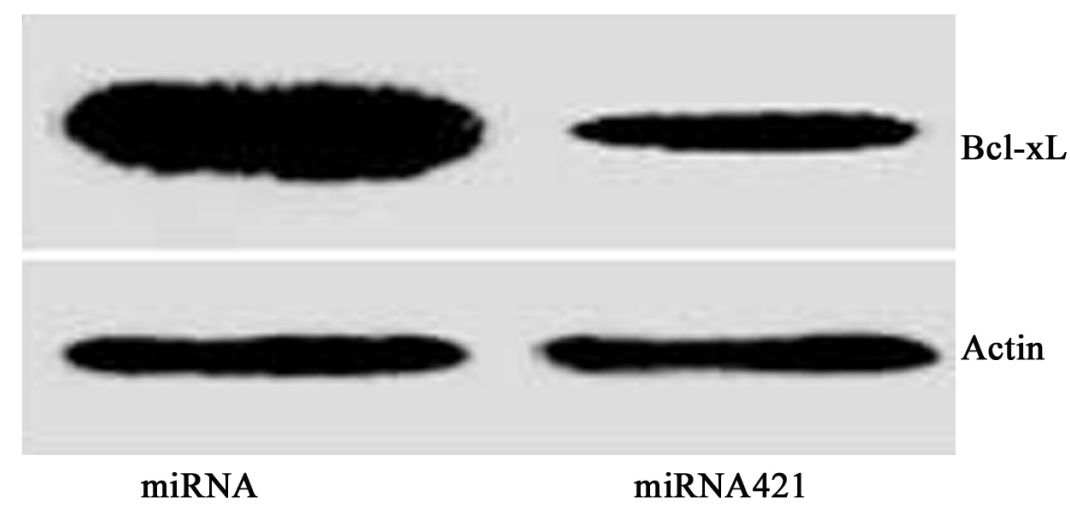

Figure 4. miRNA 421 transfection reduced Bcl-xL expression in c-33a cells.

\section{Silencing of Bcl-xL enhanced miRNA 421-induced apoptosis of c-33a cells}

Bcl-xL was silenced to investigate its role in miRNA 421-induced apoptosis of c-33a cells. Western blotting revealed that Bcl-xL levels were significantly reduced by siRNA (Figure 5 and Table 1). Expression of Bcl-xL in the c-33a-miRNA 421-siBcl-xL group was 
significantly lower than that in the c-33a-miRNA 421-control siRNA group $(\mathrm{P}=0.025)$. The results showed that decreased $\mathrm{Bcl}-\mathrm{xL}$ expression resulting from siRNA significantly increased miRNA 421-induced apoptosis of c-33a cells, in comparison to that of cells transfected with and miRNA $421(\mathrm{P}=0.014$; Figure 5).

A

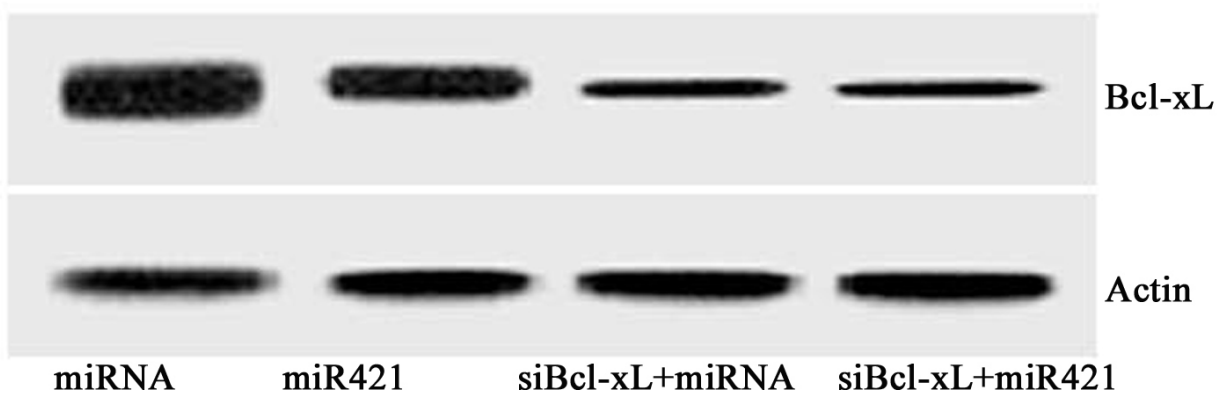

B

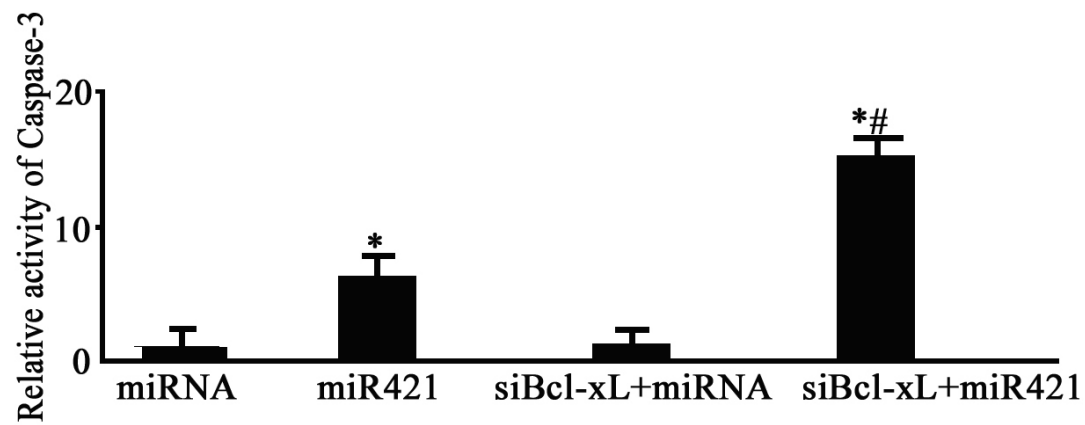

Figure 5. Silencing of Bcl-xL enhanced miRNA 421-induced apoptosis of c-33a cells. c-33a cells transfected with control miRNA, miRNA 421, miRNA $421+$ Bcl-xL small interfering RNA (siBcl-xL), or control miRNA + siBclxL. A. Expression of Bcl-xL. B. Relative activity of caspase-3. $* \mathrm{P}<0.05$ compared to the control miRNA group; \# $\mathrm{P}<0.05$ compared to the control miRNA + siBcl-xL group.

Table 1. Relative expression of Bcl-xL protein in c-33a cells transfected with small interfering RNA targeting Bcl-xL (siBcl-xL).

\begin{tabular}{l|c|c|c|c}
\hline & miRNA & miRNA 421 & siBcl-xL + miRNA & siBcl-xL + miRNA 421 \\
\hline Bcl-xL/actin & $2.54 \pm 0.22$ & $1.31 \pm 0.41^{*}$ & $0.57 \pm 0.15^{*}$ & $0.42 \pm 0.20^{*}$ \\
\hline
\end{tabular}

miRNA $=$ microRNA. $* \mathrm{P}<0.05$ compared to the miRNA group.

\section{Overexpression of Bcl-xL inhibited miRNA 421-induced apoptosis of c-33a cells}

Bcl-xL was overexpressed in c-33a cells in order to examine its effect on their miRNA 421-induced apoptosis. The results of Figure 6 and Table 2 suggested that Bcl-xL was significantly decreased in cells transfected with miRNA 421 plasmid $(\mathrm{P}<0.05)$. As shown in Figure 6, Bcl-xL was significantly overexpressed in cells transfected with both miRNA 421 and the Bcl-xL plasmid, compared to those transfected with miRNA 421 alone $(\mathrm{P}=0.018)$. The caspase- 3 activity assay revealed that $\mathrm{Bcl}-\mathrm{xL}$ overexpression significantly inhibited miRNA 421-induced apoptosis of c-33a cells $(\mathrm{P}=0.027$; Figure 6$)$. 


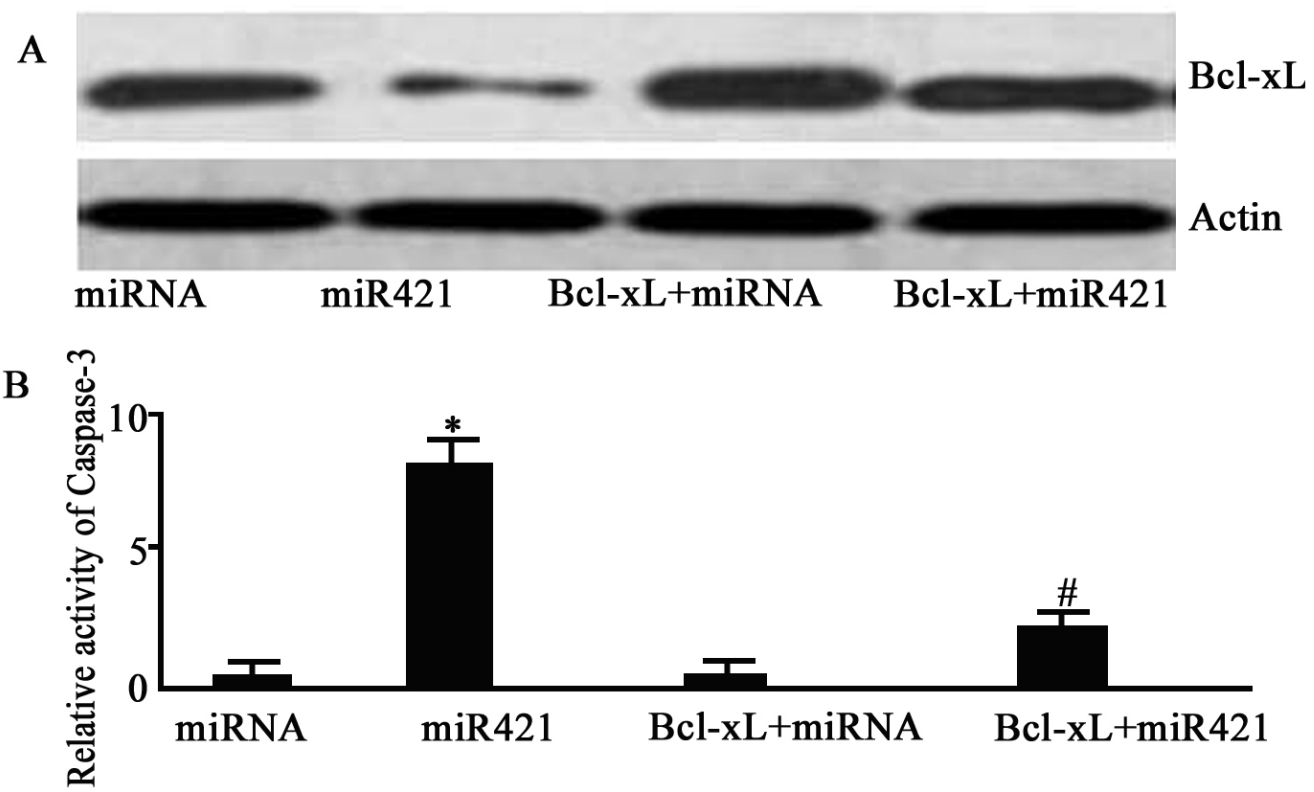

Figure 6. Overexpression of Bcl-xL inhibited miRNA 421-induced apoptosis of c-33a cells. A caspase-3 assay was used to analyze apoptosis of c-33a cells transfected with control miRNA, miRNA 421, or miRNA $421+\mathrm{a}$ Bcl-xL expression plasmid. A. Western blot of Bcl-xL expression. B. Caspase- 3 activity. $* \mathrm{P}<0.05$ compared to the control miRNA group; ${ }^{*} \mathrm{P}<0.05$ compared to the miRNA 421 group.

Table 2. Relative expression of Bcl-xL protein in c-33a cells transfected with a Bcl-xL expression plasmid.

\begin{tabular}{l|c|c|c|c}
\hline & miRNA & miRNA 421 & Bcl-xL + miRNA & Bcl-xL + miRNA 421 \\
\hline Bcl-xL/actin & $1.24 \pm 0.13$ & $0.35 \pm 0.07^{*}$ & $1.48 \pm 0.25$ & $1.31 \pm 0.18$ \\
\hline
\end{tabular}

miRNA $=$ microRNA. $* \mathrm{P}<0.05$ compared to the miRNA group.

\section{DISCUSSION}

In this study, c-33a cervical cancer cells were used as a model to study the role of miRNA 421 in this malignancy at the molecular level. Our data demonstrated that transfection with miRNA 421 reduced the viability and promoted the apoptosis of c-33a cells. This is consistent with previous studies showing that miRNAs are involved in cell growth and survival (Li et al., 2015). Few studies have examined the effects of miRNAs in cervical cancer (Li et al., 2015). miRNA-218 has been shown to inhibit the growth of cervical malignancies, and miRNA-34a influences metastasis (Geng et al., 2015; Kogo et al., 2015). Thus, miRNAs may also be involved in the occurrence and development of cervical cancer (Lao et al., 2014; Geng et al., 2015; Kogo et al., 2015).

Bcl-xL is an inhibitor of apoptosis proteins (Yang et al., 2014). Whether miRNA 421 regulates the growth of c-33a cells through regulation of Bcl-xL remains unclear (Chen et al., 2014; Liu et al., 2015). The present study showed that transfection with miRNA 421 decreased $\mathrm{Bcl}-\mathrm{xL}$ levels. Moreover, suppression and overexpression of Bcl-xL promoted and inhibited miRNA 421-induced apoptosis of c-33a cells, respectively. 
In the current study, three different methods were employed to demonstrate that BclxL plays a highly important role in the apoptosis of c-33a cells affected by miRNA 421 . First, western blotting identified a significant reduction in Bcl-xL protein levels in c-33a cells. Second, suppression of Bcl-xL enhanced miRNA 421-induced apoptosis of these cells. Last, Bcl-xL overexpression was shown to inhibit such apoptosis. These results indicate that $\mathrm{Bcl}-\mathrm{xL}$ performs a crucial function in the mechanism by which miRNA 421 promotes c-33a cell apoptosis, suggesting that it might constitute a novel target for the molecular therapy of cervical cancer (Luo et al., 2013). Other studies have reported that Bcl-xL inhibits apoptosis of cancer cells (Huang et al., 2013; Liu et al., 2015), but our investigation showed for the first time that miRNA 421 and $\mathrm{Bcl}-\mathrm{xL}$ coordinate to regulate this process.

Having not included cervical tumor tissues and adjacent normal tissues in this study, measurement of Bcl-xL protein levels in such specimens, which would have demonstrated the relationship between Bcl-xL and cervical cancer in a clinical context, was not carried out. This study also lacked data from an animal model of cervical cancer, which would have allowed us to test the efficacy of targeting miRNA 421 as a treatment for this condition. These shortcomings will be addressed in future research.

\section{CONCLUSIONS}

Transfection with miRNA 421 reduced the viability of c-33a cervical cancer cells, and induced their apoptosis by suppression of $\mathrm{Bcl}-\mathrm{xL}$ expression. Therefore, $\mathrm{Bcl}-\mathrm{xL}$ may represent a therapeutic target in cervical cancer, and our study provides a useful theoretical basis for the treatment of this disease.

\section{Conflicts of interest}

The authors declare no conflict of interest.

\section{ACKNOWLEDGMENTS}

We thank the anonymous reviewers for reviewing this manuscript.

\section{REFERENCES}

Bhattacharjya S, Roy KS, Ganguly A, Sarkar S, et al. (2015). Inhibition of nucleoporin member Nup214 expression by miR133b perturbs mitotic timing and leads to cell death. Mol. Cancer 14: 42. http://dx.doi.org/10.1186/s12943-015-0299-z

Bonetta AC, Mailly L, Robinet E, Travé G, et al. (2015). Artificial microRNAs against the viral E6 protein provoke apoptosis in HPV positive cancer cells. Biochem. Biophys. Res. Commun. 465: 658-664. http://dx.doi.org/10.1016/j. bbrc.2015.07.144

Bumrungthai S, Ekalaksananan T, Evans MF, Chopjitt P, et al. (2015). Up-regulation of miR-21 is associated with cervicitis and human papillomavirus infection in cervical tissues. PLoS One 10: 0127109 . http://dx.doi.org/10.1371/ journal.pone. 0127109

Chang YW, Chen MW, Chiu CF, Hong CC, et al. (2014). Arsenic trioxide inhibits CXCR4-mediated metastasis by interfering miR-520h/PP2A/NF-kB signaling in cervical cancer. Ann. Surg. Oncol. 21 (Suppl 4): S687-S695. http:// dx.doi.org/10.1245/s10434-014-3812-5

Chen Y, Ke G, Han D, Liang S, et al. (2014). MicroRNA-181a enhances the chemoresistance of human cervical squamous cell carcinoma to cisplatin by targeting PRKCD. Exp. Cell Res. 320: 12-20. http://dx.doi.org/10.1016/j. yexcr.2013.10.014

Genetics and Molecular Research 15 (4): gmr15048853 
Cong J, Liu R, Wang X, Jiang H, et al. (2015). MiR-634 decreases cell proliferation and induces apoptosis by targeting mTOR signaling pathway in cervical cancer cells. Artif. Cells Nanomed. Biotechnol. 14: 1-8.

Deng B, Zhang Y, Zhang S, Wen F, et al. (2015). MicroRNA-142-3p inhibits cell proliferation and invasion of cervical cancer cells by targeting FZD7. Tumour Biol. 36: 8065-8073. http://dx.doi.org/10.1007/s13277-015-3483-2

Geng D, Song X, Ning F, Song Q, et al. (2015). miR-34a inhibits viability and invasion of human papillomavirus-positive cervical cancer cells by targeting E2F3 and regulating survivin. Int. J. Gynecol. Cancer 25: 707-713. http://dx.doi. org/10.1097/IGC.0000000000000399

Honegger A, Schilling D, Bastian S, Sponagel J, et al. (2015). Dependence of intracellular and exosomal microRNAs on viral E6/E7 oncogene expression in HPV-positive tumor cells. PLoS Pathog. 11: e1004712. http://dx.doi. org/10.1371/journal.ppat.1004712

Huang F, Lin C, Shi YH and Kuerban G (2013). MicroRNA-101 inhibits cell proliferation, invasion, and promotes apoptosis by regulating cyclooxygenase-2 in Hela cervical carcinoma cells. Asian Pac. J. Cancer Prev. 14: 59155920. http://dx.doi.org/10.7314/APJCP.2013.14.10.5915

Jia LF, Gan YH and Yu GY (2016). [Relationships between microRNA expressions and prognosis in patients with tongue squamous cell carcinoma and the mechanisms microRNA regulating tongue squamous cell carcinoma biological behavior]. Beijing Da Xue Xue Bao 48: 5-9.

Kogo R, How C, Chaudary N, Bruce J, et al. (2015). The microRNA-218 Survivin axis regulates migration, invasion, and lymph node metastasis in cervical cancer. Oncotarget 6: 1090-1100. http://dx.doi.org/10.18632/oncotarget.2836

Kong Q, Wang W and Li P (2015). Regulator role of HPV E7 protein on miR-21 expression in cervical carcinoma cells and its functional implication. Int. J. Clin. Exp. Pathol. 8: 15808-15813.

Lao G, Liu P, Wu Q, Zhang W, et al. (2014). Mir-155 promotes cervical cancer cell proliferation through suppression of its target gene LKB1. Tumour Biol. 35: 11933-11938. http://dx.doi.org/10.1007/s13277-014-2479-7

Li J, Hu L, Tian C, Lu F, et al. (2015). microRNA-150 promotes cervical cancer cell growth and survival by targeting FOXO4. BMC Mol. Biol. 16: 24. http://dx.doi.org/10.1186/s12867-015-0052-6

Lin L, Cai Q, Zhang X, Zhang H, et al. (2015). Two less common human microRNAs miR-875 and miR-3144 target a conserved site of E6 oncogene in most high-risk human papillomavirus subtypes. Protein Cell 6: 575-588. http:// dx.doi.org/10.1007/s13238-015-0142-8

Liu S, Pan X, Yang Q, Wen L, et al. (2015). MicroRNA-18a enhances the radiosensitivity of cervical cancer cells by promoting radiation-induced apoptosis. Oncol. Rep. 33: 2853-2862.

Luo M, Shen D, Zhou X, Chen X, et al. (2013). MicroRNA-497 is a potential prognostic marker in human cervical cancer and functions as a tumor suppressor by targeting the insulin-like growth factor 1 receptor. Surgery 153: 836-847. http://dx.doi.org/10.1016/j.surg.2012.12.004

Pedroza-Torres A, López-Urrutia E, García-Castillo V, Jacobo-Herrera N, et al. (2014). MicroRNAs in cervical cancer: evidences for a miRNA profile deregulated by HPV and its impact on radio-resistance. Molecules 19: 6263-6281. http://dx.doi.org/10.3390/molecules 19056263

Song L, Liu S, Zeng S, Zhang L, et al. (2015). miR-375 modulates radiosensitivity of HR-HPV-positive cervical cancer cells by targeting UBE3A through the p53 pathway. Med. Sci. Monit. 21: 2210-2217. http://dx.doi.org/10.12659/ MSM.893859

Wen SY, Lin Y, Yu YQ, Cao SJ, et al. (2015). miR-506 acts as a tumor suppressor by directly targeting the hedgehog pathway transcription factor Gli3 in human cervical cancer. Oncogene 34: 717-725. http://dx.doi.org/10.1038/ onc. 2014.9

Yang L, Wang YL, Liu S, Zhang PP, et al. (2014). miR-181b promotes cell proliferation and reduces apoptosis by repressing the expression of adenylyl cyclase 9 (AC9) in cervical cancer cells. FEBS Lett. 588: 124-130. http:// dx.doi.org/10.1016/j.febslet.2013.11.019

Yu Q, Liu SL, Wang H, Shi G, et al. (2014). miR-126 Suppresses the proliferation of cervical cancer cells and alters cell sensitivity to the chemotherapeutic drug bleomycin. Asian Pac. J. Cancer Prev. 14: 6569-6572. http://dx.doi. org/10.7314/APJCP.2013.14.11.6569

Yuan W, Xiaoyun H, Haifeng Q, Jing L, et al. (2014). MicroRNA-218 enhances the radiosensitivity of human cervical cancer via promoting radiation induced apoptosis. Int. J. Med. Sci. 11: 691-696. http://dx.doi.org/10.7150/ijms.8880

Zhang J, Li S, Yan Q, Chen X, et al. (2013). Interferon- $\beta$ induced microRNA-129-5p down-regulates HPV-18 E6 and E7 viral gene expression by targeting SP1 in cervical cancer cells. PLoS One 8: e81366. http://dx.doi.org/10.1371/ journal.pone.0081366

Genetics and Molecular Research 15 (4): gmr15048853 